\title{
A Programmatic Approach to Patient Blood Management - Reducing Transfusions and Improving Patient Outcomes
}

\author{
Shannon L. Farmer ${ }^{1,2,}$, Kevin Trentino ${ }^{3}$, Axel Hofmann ${ }^{1,2,4}$, James B. Semmens ${ }^{2}$, S. Aqif Mukhtar ${ }^{2}$, \\ Gareth Prosser ${ }^{1,5}$, Jeffrey M. Hamdorf ${ }^{1}$, Sudhakar Rao ${ }^{6}$ and Michael F. Leahy ${ }^{7,8}$ \\ ${ }^{I}$ School of Surgery, Faculty of Medicine, Dentistry and Health Sciences, The University of Western Australia, Australia \\ ${ }^{2}$ Centre for Population Health Research, Faculty of Health Sciences, Curtin University, Western Australia, Australia \\ ${ }^{3}$ Performance Unit, South Metropolitan Health Service, Perth, Western Australia, Australia \\ ${ }^{4}$ Department of Anesthesiology, University Hospital Zurich, Switzerland \\ ${ }^{5}$ Department of Orthopaedic Surgery, Fremantle Hospital, Fremantle, Western Australia, Australia \\ ${ }^{6}$ Trauma Services, Royal Perth Hospital, Perth, Western Australia, Australia \\ ${ }^{7}$ Haematology Department, Fremantle Hospital, Fremantle, Western Australia, Australia \\ ${ }^{8}$ School of Medicine and Pharmacology, The University of Western Australia, Australia
}

\begin{abstract}
In July 2008, the Western Australia (WA) Department of Health embarked on a landmark 5-year project to implement a sustainable comprehensive health-system-wide Patient Blood Management Program. Fundamentally, it was a quality and safety initiative, which also had profound resource and economic implications. Unsustainable escalating direct and indirect costs of blood, potentially severe blood shortages due to changing population dynamics, donor deferrals, loss of altruism, wide variations in transfusion practice and growing knowledge of transfusion limitations and adverse outcomes necessitate a paradigm shift in the management of anemia and blood loss. The concept of patient-focused blood management is proving to be an effective force for change. This approach has now evolved to embrace comprehensive hospital-wide Patient Blood Management Programs. These programs show significant reductions in blood utilisation, and costs while achieving similar or improved patient outcomes. The WA Program is achieving these outcomes across a health jurisdiction in a sustained manner.
\end{abstract}

Keywords: Anemia, blood conservation, blood loss, blood transfusion, patient blood management, bloodless surgery, practice change.

\section{INTRODUCTION}

Patient blood management (PBM) shifts the attention in transfusion medicine from a product focus to a patient focus and managing the patient's own blood [1]. PBM is an evidence-based, patient-specific medical and surgical concept that employs a multidisciplinary multimodal team approach to optimise the patient's red cell mass, minimise blood loss and exploit and optimise the patient's physiological tolerance of anemia. Its aim is to improve patient outcomes [2-4]. There is now worldwide interest and uptake in PBM [5]. In May 2010, the sixty-third session of the decision-making body of the World Health Organisation, the World Health Assembly (WHA), adopted resolution WHA63.12 which recommended PBM to its 193 member states [6]. In 2008, the Australian National Blood Authority (NBA) commenced the development of 6 evidence-based

*Address correspondence to this author at the School of Surgery, Faculty of Medicine, Dentistry and Health Sciences, The University of Western Australia; E-mail: shannon.farmer@uwa.edu.au
Patient Blood Management Guidelines modules covering 1) Critical Bleeding/Massive Transfusion, 2) Perioperative, 3) Medical, 4) Critical Care, 5) Obstetrics and Maternity and 6) Paediatrics and Neonatology. PBM is most effective when implemented as part of a coordinated program [7-9]. Based on an exhaustive review of the literature the NBA Patient Blood Management Guidelines: Module 2 Perioperative contains an evidence-based recommendation that "Health-care services should establish a multidisciplinary, multimodal perioperative patient blood management program" [10]. Numerous reports in the literature show that these programs are achieving change, resulting in significant reductions in blood utilisation while improving patient outcomes and reducing costs (see Fig. 1) [9, 11-30]. In 2014 the Consumers, Health and Food Executive Agency of the European Union (EU) Commission undertook a project to develop an "EU Guide for Member States on Good Practices for Patient Blood Management", acknowledging the patient outcome and cost saving benefits of PBM (http://www. newsfox.com/news/20140321006). A provisional blood conservation program in Ontario Canada in 2002 was the 
first government-sponsored jurisdictional program [31]. It focused on three targeted surgical procedures namely, knee replacement surgery, aortic aneurysm surgery and elective coronary artery bypass surgery. The WA PBM Program was the world's first proposed comprehensive jurisdiction-wide program encompassing all medical and surgical specialties [32]. We outline here the rationale for the WA Program, its implementation and preliminary results. These outcomes have implications for both the developed and developing world.

\section{RATIONALE}

\section{The Pressing Need for Change in Transfusion Practice}

In 1988, Isbister highlighted the need for a paradigm change in transfusion practice $[33,34]$. An editorial in the British Medical Journal in 2002 stated that change would require a "cultural shift" at all levels of the health system including clinicians, managers and policy makers. Changing culture in transfusion practice, however, has been challenging [35]. Boucher and Hannon noted this in a 2007 paper writing that the "administration of blood products is surrounded by emotions, misconceptions, myths, and prescribing by habits" [36]. Dzik of the Massachusetts General Hospital Blood Transfusion Service in his 2002 Emily Cooley lecture published in the journal Transfusion highlighted a need for change and referred to "a verbal tradition of blood usage in which old 'rules', often perilously out of date, are used to decide when to transfuse" and "that many transfusion decisions are ill informed, outdated, or simply incorrect" '34]. New reasons for change have emerged in recent years, meaning the need for change is now more pressing than ever. Factors necessitating change include:

\section{Burgeoning Cost of Blood}

Economic modelling of transfusion presents a number of challenges and is generally poorly understood [37]. Traditionally, costing of blood has focused on direct acquisition costs - in itself a difficult cost assessment. Direct cost of the product, however, represents only a fraction of the total cost. Process cost analysis has been applied to estimate the total societal cost of blood [38, 39]. This broad costing needs to take into account not just the collecting, screening, testing and processing of blood products, but also the process of testing and administering blood products within the hospital and the associated costs of monitoring and treating adverse events of transfusion. A study conducted in two United States hospitals and two European hospitals using activity-based costing showed that the cost of administering red blood cell (RBC) transfusions within the hospital was two to four times that of the direct costs [40]. On top of the direct cost of blood and the activitybased cost of administering transfusions is the potential cost of adverse outcomes associated with transfusion. In a study of 89,996 multi-day acute-care inpatients discharged over a one year period Trentino et al. found that, after risk adjustment, the hospital costs associated with RBC transfusions represented $7.8 \%$ of the total hospital expenditure on that patient population. This

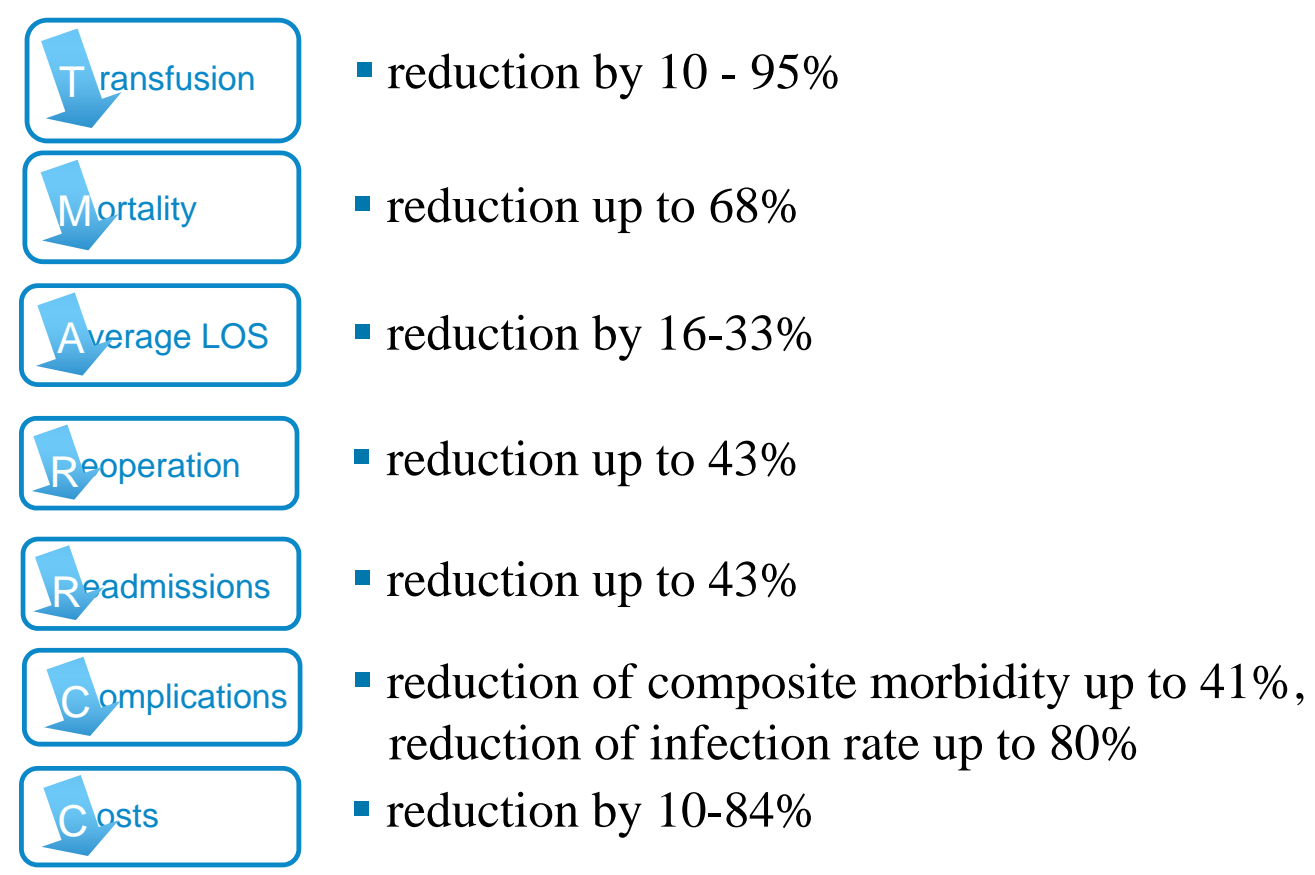

Fig. (1). Outcomes reported with comprehensive Blood Conservation/Patient Blood Management Programs. Reductions vary according to baseline utilization/practice, measure used and level of program implementation. Data compiled from: Frank 2014; Pattakos 2012; Lapar 2013; Kotze 2012; Moskowitz 2010; Reddy 2009; Brevig 2009; Ferraris 2007; Wong 2007; Ghiglione 2007; Freedman 2007; Martinez 2007; DeAnda 2006; Freedman 2005; Pierson 2004; Green 2004; Kourtzis 2004; Morgan 2004; Slappendel 2003; Van der Linden 2001; Helm 1998. 
costing does not include the cost of the blood products [41]. Accordingly, the total cost burden is becoming increasingly unsustainable.

\section{Blood Supply Challenges}

An additional challenge exists in current population dynamics. In many countries a looming socio-economic challenge relates to the so-called age-dependency ratio, a measure obtained by dividing the non-working-age population by the working-age population and multiplying by 100 . For example, data from 25 EU countries showed an age dependency ratio of 24.8 in 2005, which meant that on average 24.8 elderly persons were depending on the economic activities of 100 working individuals. Based on current population data it is estimated that this load may climb over the next 20 years to almost 40 [42]. Hofmann et al. showed how the "agedependency-ratio" can be translated to a "total transfusion dependency ratio" (TTDR) to measure the changing ratio between the donating and the nondonating population segments [37]. Studies have shown that the majority of blood is used in the older age segment of the population - a non-donating blood segment (many countries have age limits for donors with varying older age and lower age limit cutoffs) [43, 44]. In many countries, the donating age group is growing less than the rapidly growing older age segment. Farmer et al. modelled the TTDR for 11 countries to demonstrate the potential impact of an ageing population on blood supply [32]. In 2010, the TTDR for these 11 selected countries ranged from between approximately $31 \%$ to just under $45 \%$. The modelling estimated that by 2050 this could increase to between $40 \%$ and $65 \%$. This model demonstrates the supply challenge if current donation patterns remain the same and transfusion practice remains unchanged.

\section{Safety Issues}

Although the risk of known infectious agents such as human immunodeficiency virus (HIV), hepatitis $\mathrm{C}$ virus $(\mathrm{HCV})$ and hepatitis $\mathrm{B}$ virus (HBV) has been reduced to very low levels in most developed countries, the blood supply remains vulnerable to new and re-emerging infectious agents $[45,46]$. Highlighting this challenge, in the proceedings of a US Food and Drug Administration (FDA) public workshop on the risk of emerging infectious diseases (EID) for blood and blood products published in 2013, one of the participants, Dr Susan Stramer from the American Red Cross, is reported as stating: "EID agents are unique with few common characteristics. Their emergence is unpredictable, generalization about them is dangerous, vigilance is critical, and one solution does not fit all situations" [47]. Additionally, transfusion-related circulatory overload (TACO), transfusion-related acute lung injury (TRALI), wrong blood component transfused, acute transfusion reactions and bacterial contamination of blood remain the leading causes of transfusion-related death and major morbidity [48].

\section{Patient Outcome Issues}

While blood transfusion is potentially life-saving in the setting of critical bleeding and bone marrow failure, reviews of the literature demonstrate evidence to support benefit for transfusion in the majority of clinical settings in which it is given is sparse [49-51]. Recent systematic

Table 1. Adverse outcomes reported to be associated with red blood cell transfusion.

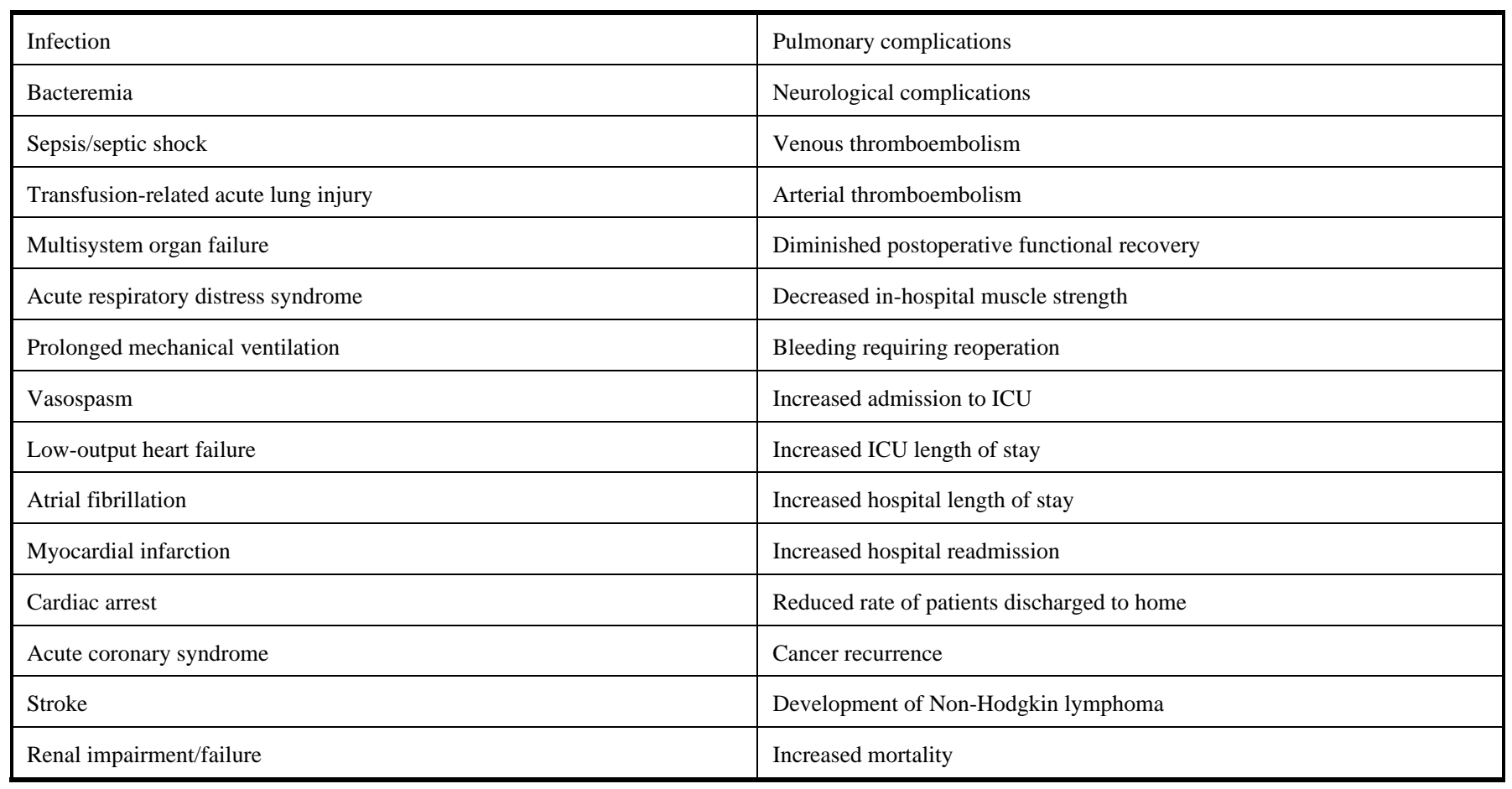


reviews and meta-analyses of randomized controlled trials that compare hemoglobin $(\mathrm{Hb})$ based liberal transfusion thresholds with restrictive transfusion thresholds establish no benefit from liberal transfusion. These meta-analyses, however, have identified possible harm from liberal transfusion. A 2012 review found liberal transfusion thresholds increased infection and inhospital mortality [52]. A 2014 review and meta-analysis found that when compared with more restrictive transfusion thresholds, liberal transfusion increased the incidence of acute coronary syndrome, pulmonary edema, re-bleeding, bacterial infection, in-hospital mortality, 30-day mortality, and total mortality [53].

The International Consensus Conference on Transfusion Outcomes (ICCTO) was convened to try to determine from the literature when RBC transfusion may be beneficial in improving patient outcomes, when it is not beneficial and when it may be harmful [54]. A systematic review of the literature published over 13 years identified 494 studies for analysis. The 15-member panel of international experts used the RAND/UCLA Appropriateness Method to determine the appropriateness (defined as likely to improve the patients health outcome) of RBC transfusion in 450 clinical scenarios in which transfusion is most commonly considered. The analysis was confined to non-actively bleeding patients to avoid the confounding of critical bleeding. Based on the literature, the expert panel concluded that in only $11.8 \%$ of the 450 clinical scenarios was transfusion likely to improve patient health outcomes. In $59.3 \%$ of the scenarios transfusion was determined to not likely improve health outcomes, even likely to harm. In $28.9 \%$ of the scenarios, it was found to be uncertain whether transfusion would be beneficial, with more research required to make definitive conclusions.

Of greater concern is a growing body of large phase 4 retrospective and prospective clinical observational studies comparing transfused patients with nontransfused patients after controlling for confounding variables showing transfusion per se to be an independent risk factor for adverse patient outcomes (see Table $\mathbf{1}$ for a list of adverse outcomes associated with transfusion) [49]. While there are inherent limitations with observational studies, these large real world studies play an important role in identifying safety issues - issues that RCTs are often too small to pick up $[55,56]$.

An exhaustive systematic review of the literature was conducted for the development of the Australian Patient Blood Management Guidelines: Module 2 Perioperative to answer the clinical question: "In patients undergoing surgery, what is the effect of RBC transfusion on patient outcomes?" [10]. This review found that in cardiac and non-cardiac surgery, RBC transfusion is independently associated with increased morbidity, intensive care unit (ICU) and hospital length of stay and mortality. Many of these studies showed a dose-response relationship, with the risks increasing with each unit given.

Recent studies have identified that even small amounts of transfusion (1 or 2 units) may have a negative impact on patient health outcomes, with an associated increased risk of mortality, wound problems, pulmonary complications, pneumonia, sepsis/septic shock, stroke, renal dysfunction/ failure, atrial fibrillation, prolonged ventilation, reoperation for bleeding, ICU and hospital length of stay [57-60].

Mechanisms suggested to explain the adverse outcomes associated with transfusion include the physical and chemical changes that take place with removal and storage of blood (referred to as the "storage lesion") and transfusion-related immunomodulation (TRIM) [61-67]. The link between TRIM and postoperative infection is considered causal and the link between TRIM and cancer recurrence is considered likely [67].

If the link between transfusion and adverse outcomes is causal, adverse outcomes may represent the largest clinical and economic burden of inappropriate transfusion [56]. Accordingly, for these and other reasons, authorities are now recommending that efforts should be directed at minimising or avoiding transfusions wherever possible [9].

\section{Variations in Transfusion Practice and Inappropriate Transfusions}

Adverse outcomes associated with transfusion are of particular concern, given the wide variations in transfusion practice that exist between countries and institutions [68-73]. Red blood cell transfusion rates vary from $9 \%$ to $92 \%$ in orthopedic surgery, $17 \%$ to $82 \%$ in colorectal surgery, $20 \%$ to $53 \%$ in critical care and $0 \%$ to $28 \%$ in acute coronary syndrome [74-78]. Frank et al. found wide variation in transfusion practice even between clinicians within the same institution [79]. This wide variation in transfusion practice in similar patient populations suggests that a large percentage of transfusions may be inappropriate and avoidable. An inappropriate transfusion offers no benefit - only risk to the patient and cost to the community.

\section{Mechanism for Change - Hospital-Wide Comprehensive Patient Blood Management Programs}

The international experience suggests that one of the most effective ways to bring about change in practice involves establishing formal, comprehensive, hospitalwide Blood Conservation/PBM programs [7, 8, 80]. These coordinated programs adopt aggressive education strategies enabling all stakeholders - including patients and all clinical and non-clinical hospital staff - to be fully informed of current evidence on the risks and benefits of transfusion along with measures to minimise blood loss and utilise appropriate blood management options. They implement an integrated multidisciplinary, multimodal medical/surgical approach that has as its focus individualised patient care that includes careful stewardship of the patient's own blood. The aim of this approach is to improve patient outcomes [1]. As an editorial by Frenzel et al. in Current Opinion in Anaesthesiology put it "Our own blood is still the best thing to have in our veins" [81]. 
Essential to a successful, comprehensive, PBM program is a committed hospital administration, personnel to coordinate and manage the program, and a full team of well informed and motivated physicians, nurses, technicians and other support staff. A hospital-wide program conjoins all departments and staff including departments of surgery, anesthesia, hematology, critical care and pharmacy, along with the pathology laboratory, transfusion service and the blood bank. A formal program structure is essential to facilitate this multidisciplinary team approach [7, 82].

A Patient Blood Management Program identifies patients at risk of transfusion and constructs a treatment plan aimed at minimising or eliminating such exposure. The program provides education for patients to enable them to understand their blood management treatment options and decisions, improving their satisfaction and comfort with the treatment process. A multidisciplinary team draws on multiple strategies to minimise blood loss, maximise hemopoiesis and manage oxygen needs of the individual patient. A "culture" is created, from administration through senior and junior clinical staff, nursing and allied health, in which allogeneic transfusion, like any other tissue transplant, is the last resort, not the first reflexive action.
PBM is built around three pillars [4, 83]:

1. Optimise the patient's red cell mass

2. Minimise blood loss

3. Exploit and optimise the tolerance of anemia

These three pillars are applied in three integrated phases: 1) the pre-treatment phase, 2) the treatment phase, and 3) the post-treatment phase.

Much has been written in the literature and in textbooks about this integrated approach and a detailed description is beyond the scope of this article [4, 7, 8, 80, 83-85].

\section{IMPLEMENTATION OF THE WA PBM PROGRAM}

The WA PBM Program drew on the accumulated international experience in $\mathrm{PBM}$ and $\mathrm{PBM}$ programs to implement for the first time a comprehensive state-wide program. It was based on established and proven models [8] including a successful Blood Conservation Program established by one of the authors (SF) at a WA private hospital in 1990 [7]. The Program's aim was to improve patient outcomes while reducing costs. The initial implementation was a five-year project designed to produce a sustainable program. It was implemented utilising professional change management principles [86]. Effective leadership

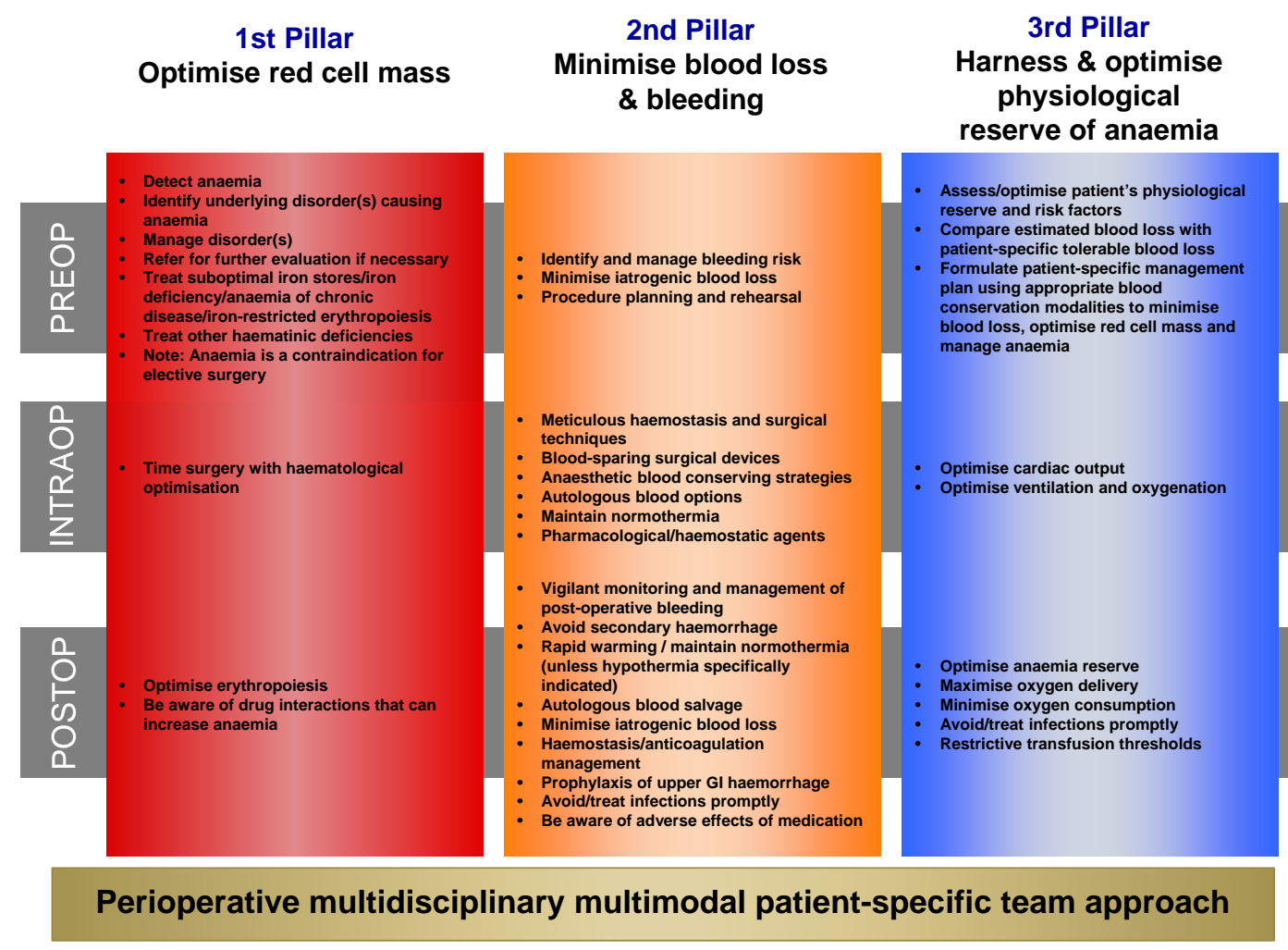

Fig. (2). The 3-pillar 9-field matrix of perioperative patient blood management. The matrix was designed for the Western Australia Patient Blood Management Program to assist in the clinical implementation of the multiple PBM strategies. These strategies are considered in the perioperative period in a patient/procedure specific context. [Adapted from Hofmann A, Friedman D, Farmer S. Western Australian Patient Blood Management Project 2008-2012: analysis, strategy, implementation and financial projections. Western Australia Department of Health 2007; 1-154. Isbister has adapted this perioperative matrix for wider clinical application, for example medical/haematological patient populations (Isbister J. The three-pillar matrix of patient blood management. ISBT Science Series. 2015;10(Suppl. 1):286-94)]. 
was provided in the Program design with executive sponsorship by the Chief Medical Officer of the time, Dr Simon Towler. Clinical leadership also included a State PBM Medical Director and a State PBM Nurse Coordinator along with a PBM Medical Director and a PBM Nurse Coordinator within each major hospital and servicing each Area Health Service. The Patient Blood Management Guidelines: Module 2 Perioperative (Page 71) highlights the major role anesthesiologists play in a PBM Program. Anesthesiologists played a key role in the Program with 3 tertiary-care hospitals appointing them as medical codirectors. The program also engaged key opinion leaders from multiple disciplines as a Clinical Reference Group. Multiple education and communication strategies for both healthcare providers and consumers were developed, including an informative website (http://www.health.wa. gov.au/bloodmanagement/home/). Clinical education and perioperative clinical practice implementation was structured around a 3-pillar 9-field matrix of the multiple perioperative PBM strategies (see Fig. 2). Surgical hemostasis workshops were developed and run at the State's Clinical Training and Evaluation Centre (CTEC - http://www.ctec.uwa.edu.au) during the early part of the program to address the second pillar of PBM namely, reducing blood loss. PBM educational road shows were conducted at all major hospital departments to inform and engage physicians at the clinical coal face. Effective data collection and monitoring systems were developed for benchmarking, continuous practice improvement and risk management [87]. Systems were re-engineered to allow timely optimisation of patient's hemoglobin and iron stores and bleeding risk assessment prior to treatment.
Details of program structure and implementation are discussed in more detail elsewhere [32, 88].

\section{RESULTS FROM THE WA PBM PROGRAM}

The WA PBM Program was announced in November 2008 in the State that had one of the lowest transfusion rates in the developed world [32]. However, issuance had been steadily increasing due in part to a rapidly growing population. Early reports showed that, with the introduction of the program, this upward trend was arrested and trended downwards $[32,88]$. Four years into the program total RBC issuance to the State had decreased from 70,143 units to 65,742 . Historical data, projected age distribution and population increases had predicted $\mathrm{RBC}$ issuance would have reached about 78,000 units by 2012 . RBC issuance to the 19 capital city hospitals, of which the five major tertiary care hospitals were the main preliminary focus of the Program, decreased from 38,525 to 34,282 despite a $22.9 \%$ increase in case-mix-adjusted inpatient activity or weighted separations [32]. In the final year of the project (2012-13) total issuance for the State was down to 64,064 and issuance for 2013-14 was 54,763. This yearly decrease was despite an average annual population increase of approximately 3\% (see Fig. 3).

Transfusion services measure blood utilisation of countries and jurisdictions in units transfused per 1000 population. Data available at the commencement of the WA Program showed RBC transfusion rates for Denmark, Germany, Austria, United States and the United Kingdom as being $60.0,57.3,52.9,48.0$ and 36.3 respectively. RBC

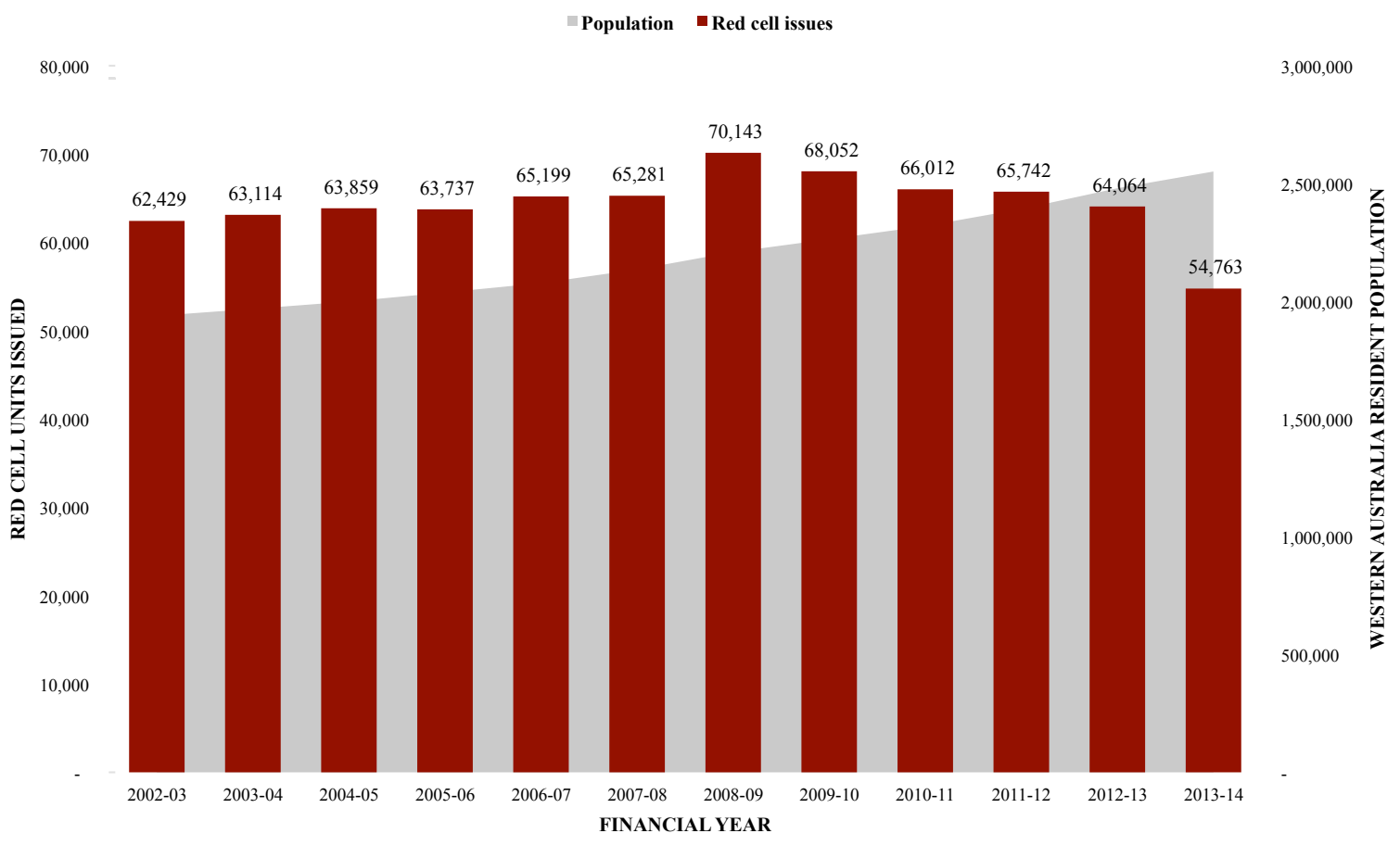

Fig. (3). Red blood cell issues data and resident population data for the State of Western Australia 2002-03 to 2013-14. Red blood cell issuance data published and unpublished National Blood Authority (Australia) data printed with permission. Issuance of red blood cells was progressively increasing in Western Australia. With the introduction of the Patient Blood Management Program in 2008-09 this upward trend was arrested and issuance has decreased each year despite an annual population increase. 
issuance for Western Australia was 31.8/1000 (year 200809 ). This had decreased each year to $25.8 / 1000$ by the end of the 5-year project. This decrease has been sustained with issuance reaching 21.5/1000 for the year 2013-14 (see Fig. 4). Reductions have also been seen in fresh frozen plasma (FFP) issuance while cryoprecipitate issuance increased. This may partly be explained by practice change from using FFP to fibrinogen-containing cryoprecipitate in bleeding patients. Platelet issuance has remained about the same (see Fig. 5.)

Initial data presented by one of the main teaching hospitals highlights outcomes associated with implementation. These data focused on one of the early patient groups targeted post program introduction: knee replacement (diagnostic related group I04). The data showed a significant reduction in the proportion of patients transfused from $10.5 \%$ pre PBM implementation to $2.2 \%$ post implementation $(\mathrm{p}<0.001)$. In addition to reducing the transfusion rate, the data suggests evidence of improved patient outcomes. Reduction in unadjusted mean hospital length of stay fell from 8.74 days to 7.58 days ( $\mathrm{p}=0.002$ ). Using Classification of Hospital Acquired Diagnoses data [89] four key areas of hospital-acquired complications were identified: hospitalacquired anemia, post-procedural complications, cardiovascular complications and respiratory complications. The composite incidence of these complications was significantly reduced from $15.3 \%$ to $10.2 \%$ post PBM implementation $(\mathrm{p}=0.031)$. Analysed individually this was made up of reductions in the incidence of post-procedural complications from $6.7 \%$ to $3.1 \%(\mathrm{p}=0.021)$ and small (non-statistically significant) reductions in cardiovascular and respiratory complications (5.4\% vs 5.2\%; $\mathrm{p}=0.905$ and $2.8 \%$ vs. $2.5 \%$; $\mathrm{p}=0.763$ respectively) [90].

While the literature demonstrates an association between RBC transfusion and increased length of stay and hospital acquired complications, a reduction in transfusion from $10.5 \%$ to $2.2 \%$ cannot fully explain the improved outcomes seen in this cohort study. Likely, contributing to these is the improved care of the PBM approach namely, careful patient evaluation and optimisation prior to surgery, meticulous surgical technique and use of hemostatic agents to reduce blood loss intraoperatively and greater use of intravenous iron to manage postoperative anemia.

\section{CONCLUSION}

Patient-focused blood management is increasingly being seen as the new standard of care [4]. Patient blood management is an evidence-based concept as opposed to a behaviour-based paradigm [91]. It can result in significant reductions in transfusion and cost savings while improving patient outcomes. However, implementation requires a cultural shift among all levels of the health care system. If we fail to change the paradigm, as a 2006 editorial in Critical Care Medicine stated, "we do so to the profound detriment of patients" [92].
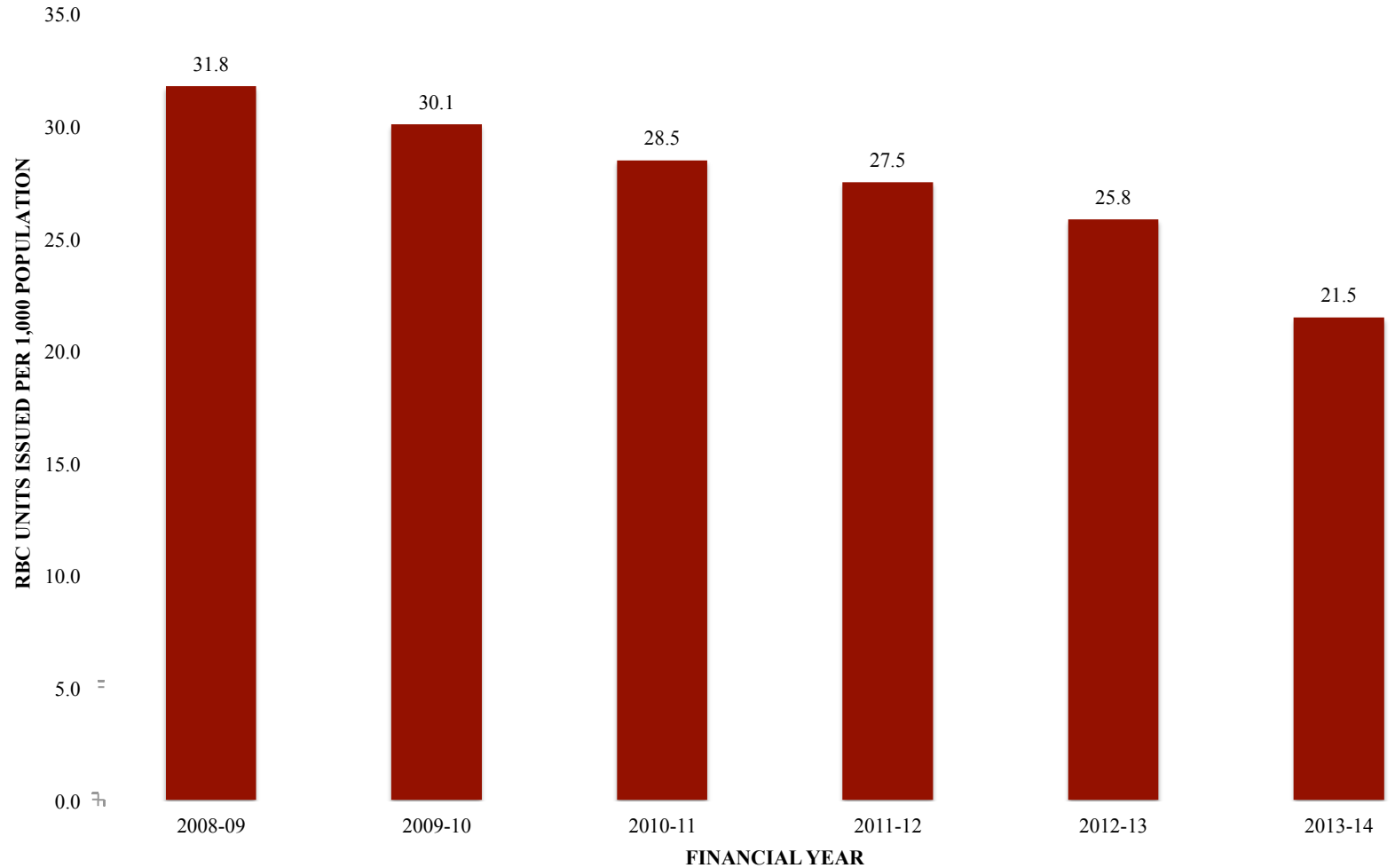

Fig. (4). Red blood cell units issued per 1,000 population for the State of Western Australia 2008-09 to 2013-14 (published and unpublished data). Printed with permission National Blood Authority (Australia). Issuances have decreased every year since the beginning of the Western Australia Patient Blood Management Program, despite beginning with the lowest issuance rate per 1,000 population in the developed world. 


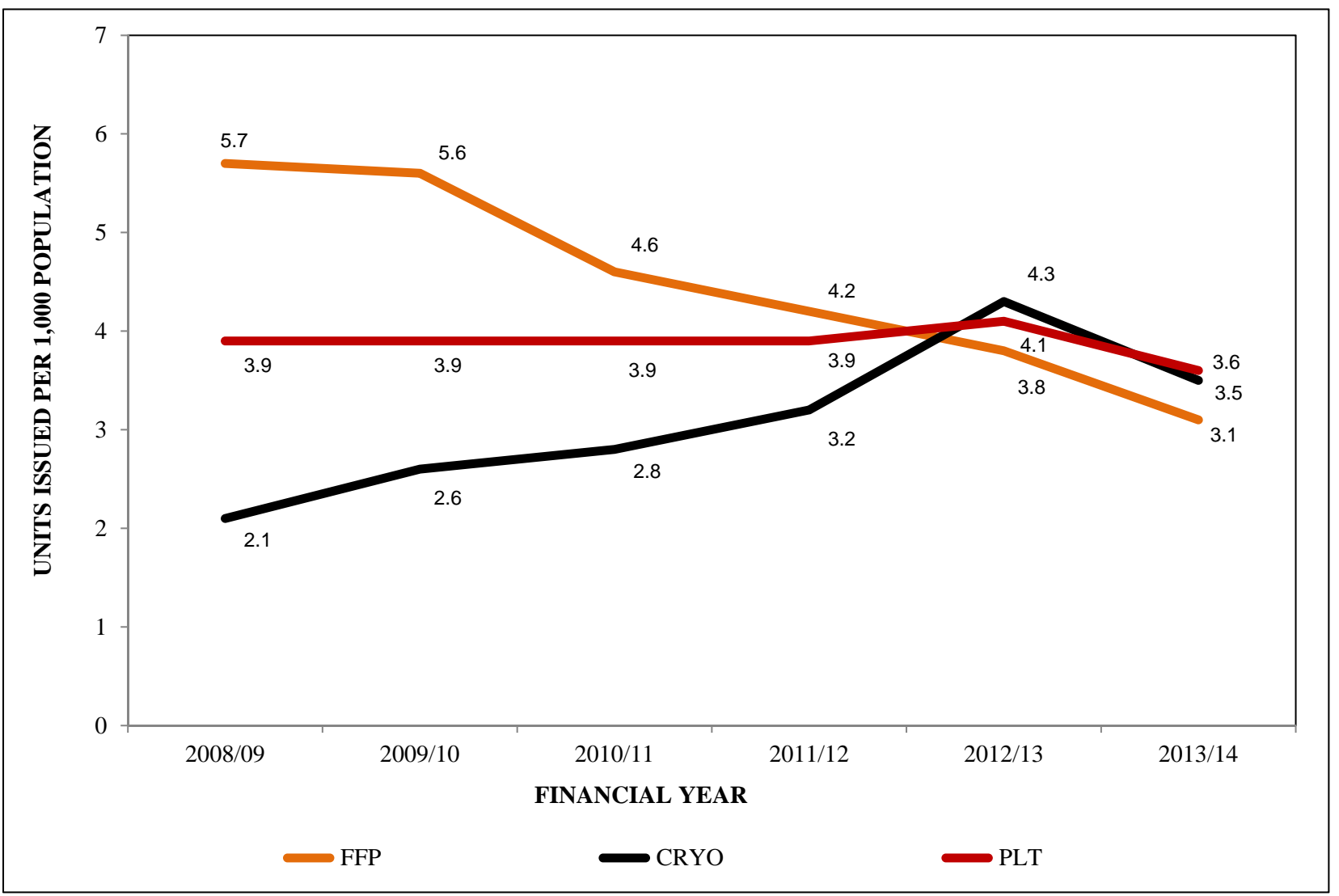

Fig. (5). Fresh frozen plasma (FFP), cryoprecipitate and platelet units issued per 1,000 population for the State of Western Australia 2008-09 to 2013-14 (published and unpublished data). Printed with permission National Blood Authority (Australia).

\section{CONFLICT OF INTEREST}

No funding was received for the preparation of this manuscript. Kevin Trentino, James Semmens, Aqif Mukhtar, Gareth Prosser, Jeffrey Hamdorf, Sudhakar Rao and Michael Leahy confirm they have no conflict of interest. SF has received consulting/ lecture honoraria or travel support from Western Australia, Queensland, New South Wales and South Australia Departments of Health, Australian Red Cross Blood Service, Australian National Blood Authority, Australian Jurisdictional Blood Committee, Medical Society for Blood Management, Society for the Advancement of Blood Management, Fremantle General Practice Network, Western Australia, Thieme, Stuttfart Germany, Elsevier Science USA, Haematology Society of Australia and New Zealand/ Australia and New Zealand Society of Blood Transfusion, Novo Nordisk, Vifor Pharma Ltd., Johnson \& Johnson Ethicon Biosurgery. He is an Associate Investigator, Chief Investigator and Principal Investigator of 3 government sponsored research trials and a member of the Expert Panel for the European Commission Patient Blood Management Project. Axel Hofmann has in the past 5 years received honoraria and/or travel support for professional services related to program implementation, health economic analyses, outcomes research as well as lecturing from the following companies and legal entities: Amgen $\mathrm{GmbH}$, Switzerland, Australian Red Cross Blood Service, Australia, Austrian Institute of Technology $\mathrm{GmbH}$, Austria, CSL
Behring Lda, Portugal, BBraun AG, Germany, CSL Behring GmbH,, Germany, Ethicon Biosurgery, USA, Fresenius Kabi GmbH, Germany, Hospira Ltd, United Kingdom, Johnson \& Johnson Medical Pty Ltd, Australia, JW Pharmaceuticals, South Korea, National Blood Authority, Australia, Northern Valley Anesthesiology, USA, Novo Nordisk Pharmaceuticals Pty Ltd, Australia, TEM GmbH, Germany, United States Department of Health and Human Services, USA, Vifor Pharma AG, Switzerland, Vifor Pharma Österreich GmbH, Austria, Vifor Deutschland $\mathrm{GmbH}$, Germany, Various International Consulting Firms, Various Professional Medical Societies, Various Teaching and University Hospitals, Western Australia Department of Health, Australia.

\section{ACKNOWLEDGEMENTS}

The Western Australia Chief Medical Officer, Dr Simon Towler, during whose office the Program was conceived and implemented. The current CMO, Dr Gary Geelhoed. The PBM Medical Directors, State PBM Clinical Coordinator (Trudi Gallagher), PBM Clinical Nurse Consultants, the Western Australia Department of Health and all the clinicians and support staff for their commitment to patient blood management, the Program and patient care. The authors gratefully acknowledge the National Blood Authority (Australia) for supplying RBC, FFP, Cryoprecipitate and platelet issues data. There was no funding for this manuscript. 


\section{REFERENCES}

[1] Isbister JP. The three-pillar matrix of patient blood management an overview. Best Pract Res Clin Anaesthesiol 2013; 27(1): 69-84.

[2] Hofmann A, Farmer S, Shander A. Five drivers shifting the paradigm from product-focused transfusion practice to patient blood management. Oncologist 2011; 16 (Suppl 3): 3-11.

[3] Hofmann A, Farmer S, Towler SC. Strategies to preempt and reduce the use of blood products: an Australian perspective. Curr Opin Anaesthesiol 2012; 25(1): 66-73.

[4] Thomson A, Farmer S, Hofmann A, et al. Patient Blood Management - a new paradigm for transfusion medicine? ISBT Sci Ser 2009; 4: 423-35.

[5] Waters JH, Ness PM. Patient blood management: a growing challenge and opportunity. Transfusion 2011; 51(5): 902-3.

[6] Sixty-third World Health Assembly, Resolution WHA63.12, Availability, safety and quality of blood products 2010. Available from: http://apps.who.int/gb/ebwha/pdf_files/WHA63-REC1/WHA63 REC1-en.pdf

[7] Martyn V, Farmer SL, Wren MN, et al. The theory and practice of bloodless surgery. Transfus Apher Sci 2002; 27(1): 29-43.

[8] Goodnough LT, Shander A. Blood management. Arch Pathol Lab Med 2007; 131(5): 695-701.

[9] Ferraris VA, Ferraris SP, Saha SP, et al. Perioperative blood transfusion and blood conservation in cardiac surgery: the Society of Thoracic Surgeons and The Society of Cardiovascular Anesthesiolo-gists clinical practice guideline. Ann Thorac Surg 2007; 83(5 Suppl): S27-86.

[10] NBA. Patient Blood Management Guidelines: Module 2 Perioperative. Canberra, Australia: National Blood Authority (NBA); 2012. Available from: http://www.blood.gov.au/pbmmodule-2

[11] LaPar DJ, Crosby IK, Ailawadi G, et al. Blood product conservation is associated with improved outcomes and reduced costs after cardiac surgery. J Thorac Cardiovasc Surg 2013; 145(3): 796-803.

[12] Kotze A, Carter LA, Scally AJ. Effect of a patient blood management programme on preoperative anaemia, transfusion rate, and outcome after primary hip or knee arthroplasty: a quality improvement cycle. Br J Anaesth 2012; 108(6): 943-52.

[13] Moskowitz DM, McCullough JN, Shander A, et al. The impact of blood conservation on outcomes in cardiac surgery: is it safe and effective? Ann Thorac Surg 2010; 90(2): 451-8.

[14] Reddy SM, Talwar S, Velayoudam D, et al. Multi-modality blood conservation strategy in open-heart surgery: an audit. Interact Cardiovasc Thorac Surg 2009; 9(3): 480-2.

[15] Brevig J, McDonald J, Zelinka ES, et al. Blood transfusion reduction in cardiac surgery: multidisciplinary approach at a community hospital. Ann Thorac Surg 2009; 87(2): 532-9.

[16] Wong CJ, Vandervoort MK, Vandervoort SL, et al. A clusterrandomized controlled trial of a blood conservation algorithm in patients undergoing total hip joint arthroplasty. Transfusion 2007; 47(5): 832-41.

[17] Ghiglione M. Blood management: a model of excellence. Clin Leadersh Manag Rev 2007; 21(2): E2.

[18] Freedman J, Luke K, Escobar M, et al. Experience of a network of transfusion coordinators for blood conservation (Ontario Transfusion Coordinators [ONTraC]). Transfusion 2008; 48(2): 237-50.

[19] Martinez V, Monsaingeon-Lion A, Cherif K, et al. Transfusion strategy for primary knee and hip arthroplasty: impact of an algorithm to lower transfusion rates and hospital costs. $\mathrm{Br} \mathrm{J}$ Anaesth 2007; 99(6): 794-800.

[20] DeAnda A Jr., Baker KM, Roseff SD, et al. Developing a blood conservation program in cardiac surgery. Am J Med Qual 2006; 21(4): 230-7.

[21] Freedman J, Luke K, Monga N, et al. A provincial program of blood conservation: The Ontario Transfusion Coordinators (ONTraC). Transfus Apher Sci 2005; 33(3): 343-9.
[22]

[33] Mortimer PP. Making blood safer. BMJ 2002; 325(7361): 400-1.

[34] Farmer SL, Isbister JP, Leahy MF. History of transfusion and patient blood management. In: Jabbour $\mathrm{N}$, ed. Transfusion free medicine and surgery. $2^{\text {nd }}$ ed. Malden, Mass: Wiley-Blackwell 2014.

[35] Boucher BA, Hannon TJ. Blood management: a primer for clinicians. Pharmacotherapy 2007; 27(10): 1394-411.

[36] Dzik WH. Emily Cooley Lecture 2002: transfusion safety in the hospital. Transfusion 2003; 43(9): 1190-9.

[37] Hofmann A, Farmer S, Shander A. Cost-effectiveness in haemotherapies and transfusion medicine. ISBT Sci Ser 2009; 4: 423-35.

[38] The cost of blood: multidisciplinary consensus conference for a standard methodology. Transfus Med Rev 2005; 19(1): 66-78.

[39] Shander A, Hofmann A, Gombotz H, et al. Estimating the cost of blood: past, present, and future directions. Best Pract Res Clin Anaesthesiol 2007; 21(2): 271-89.

[40] Shander A, Hofmann A, Ozawa S, et al. Activity-based costs of blood transfusions in surgical patients at four hospitals. Transfusion 2010; 50: 753-65.

[41] Trentino KM, Farmer SL, Swain SG, et al. Increased hospital costs associated with red blood cell transfusion. Transfusion 2015; 55(5):1082-9.

[42] EUPHIX European Union Public Health Information System Available at: http://preview.euphix.org/object_class/euph_population by gender age.html [Access May 2015].

[43] Cobain TJ, Vamvakas EC, Wells A, Titlestad K. A survey of the demographics of blood use. Transfus Med 2007; 17(1): 1-15.

[44] Ali A, Auvinen MK, Rautonen J. The aging population poses a global challenge for blood services. Transfusion 2010; 50(3): 5848.

[45] Alter HJ, Stramer SL, Dodd RY. Emerging infectious diseases that threaten the blood supply. Semin Hematol 2007; 44(1): 32-41.

[46] Blajchman MA, Vamvakas EC. The continuing risk of transfusiontransmitted infections. N Engl J Med 2006; 355(13): 1303-5. 
[47] Gallagher LM, Ganz PR, Yang H, et al. Advancing risk assessment for emerging infectious diseases for blood and blood products: proceedings of a public workshop. Transfusion 2013; 53(2): 45563.

[48] Vamvakas EC, Blajchman MA. Blood still kills: six strategies to further reduce allogeneic blood transfusion-related mortality. Transfus Med Rev 2010; 24(2): 77-124.

[49] Farmer S, Isbister J, Hofmann A. Transfusion and outcomes. In: Gombotz H, Zacharowski K, Spahn D, eds. Patient Blood Management. $2^{\text {nd }}$ ed. Rudigerstr, Stuttgart: Georg Thieme Verlag KG 2014 (in press).

[50] Curry N, Stanworth S, Hopewell S, et al. Trauma-induced coagulopathy--a review of the systematic reviews: is there sufficient evidence to guide clinical transfusion practice? Transfus Med Rev 2011; 25(3): 217-31 e2

[51] Napolitano LM, Kurek S, Luchette FA, et al. Clinical practice guideline: red blood cell transfusion in adult trauma and critical care. J Trauma 2009; 67(6): 1439-42.

[52] Carson JL, Carless PA, Hebert PC. Transfusion thresholds and other strategies for guiding allogeneic red blood cell transfusion. Cochrane Database Syst Rev 2012; 4: CD002042.

[53] Salpeter SR, Buckley JS, Chatterjee S. Impact of more restrictive blood transfusion strategies on clinical outcomes: a meta-analysis and systematic review. Am J Med 2014; 127(2): 124-31 e3.

[54] Shander A, Fink A, Javidroozi M, et al. Appropriateness of allogeneic red blood cell transfusion: the international consensus conference on transfusion outcomes. Transfus Med Rev 2011; 25(3): 232-46 e53.

[55] Vlahakes GJ. The value of phase 4 clinical testing. N Engl J Med 2006; 354(4): 413-5.

[56] Isbister JP, Shander A, Spahn DR, et al. Adverse blood transfusion outcomes: establishing causation. Transfus Med Rev 2011; 25(2): 89-101.

[57] Bernard AC, Davenport DL, Chang PK, et al. Intraoperative transfusion of $1 \mathrm{U}$ to $2 \mathrm{U}$ packed red blood cells is associated with increased 30-day mortality, surgical-site infection, pneumonia, and sepsis in general surgery patients. J Am Coll Surg 2009; 208(5): 931-7, 7 e1-2.

[58] Ferraris VA, Davenport DL, Saha SP, et al. Intraoperative transfusion of small amounts of blood heralds worse postoperative outcome in patients having noncardiac thoracic operations. Ann Thorac Surg 2011; 91(6): 1674-80.

[59] Ferraris VA, Davenport DL, Saha SP, et al. Surgical outcomes and transfusion of minimal amounts of blood in the operating room. Arch Surg 2012; 147(1): 49-55.

[60] Paone G, Likosky DS, Brewer R, et al. Transfusion of 1 and 2 units of red blood cells is associated with increased morbidity and mortality. Ann Thorac Surg 2014; 97(1): 87-93.

[61] Tinmouth A, Chin-Yee I. The clinical consequences of the red cell storage lesion. Transfus Med Rev 2001; 15(2): 91-107.

[62] Gladwin MT, Kanias T, Kim-Shapiro DB. Hemolysis and cell-free hemoglobin drive an intrinsic mechanism for human disease. $\mathrm{J}$ Clin Invest 2012; 122(4): 1205-8.

[63] Tsai AG, Hofmann A, Cabrales P, Intaglietta M. Perfusion vs. oxygen delivery in transfusion with "fresh" and "old" red blood cells: the experimental evidence. Transfus Apher Sci 2010; 43(1): 69-78.

[64] Donadee C, Raat NJ, Kanias T, et al. Nitric oxide scavenging by red blood cell microparticles and cell-free hemoglobin as a mechanism for the red cell storage lesion. Circulation 2011; 124(4): 465-76.

[65] Reynolds JD, Ahearn GS, Angelo M, et al. S-nitrosohemoglobin deficiency: a mechanism for loss of physiological activity in banked blood. Proc Natl Acad Sci U S A 2007; 104(43): 17058-62.

[66] Yalcin O, Ortiz D, Tsai AG, et al. Microhemodynamic aberrations created by transfusion of stored blood. Transfusion 2013; 54(4): 1051-27.
[67] Refaai MA, Blumberg N. Transfusion immunomodulation from a clinical perspective: an update. Expert Rev Hematol 2013; 6(6): 653-63.

[68] Shehata N, Wilson K, Mazer CD, et al. The proportion of variation in perioperative transfusion decisions in Canada attributable to the hospital: [La proportion de variation dans les pratiques transfusionnelles perioperatoires au Canada imputable aux hopitaux]. Can J Anaesth 2007; 54(11): 902-7.

[69] Daly DJ, Myles PS, Smith JA, et al. Anticoagulation, bleeding and blood transfusion practices in Australasian cardiac surgical practice. Anaesth Intens Care 2007; 35(5): 760-8.

[70] Grey DE, Smith V, Villanueva G, et al. The utility of an automated electronic system to monitor and audit transfusion practice. Vox Sang 2006; 90(4): 316-24.

[71] Gombotz H, Rehak PH, Shander A, Hofmann A. Blood use in elective surgery: the Austrian benchmark study. Transfusion 2007; 47(8): 1468-80.

[72] Rao SV, Chiswell K, Sun JL, et al. International variation in the use of blood transfusion in patients with non-ST-segment elevation acute coronary syndromes. Am J Cardiol 2008; 101(1): 25-9.

[73] Gombotz H, Rehak PH, Shander A, Hofmann A. The second Austrian benchmark study for blood use in elective surgery: results and practice change. Transfusion 2014; 54(10 Pt 2): 2646-57.

[74] Spahn DR. Anemia and patient blood management in hip and knee surgery: a systematic review of the literature. Anesthesiology 2010 113(2): 482-95.

[75] Bennett-Guerrero E, Zhao Y, O'Brien SM, et al. Variation in use of blood transfusion in coronary artery bypass graft surgery. JAMA 2010; 304(14): 1568-75

[76] Acheson AG, Brookes MJ, Spahn DR. Effects of allogeneic red blood cell transfusions on clinical outcomes in patients undergoing colorectal cancer surgery: a systematic review and meta-analysis. Ann Surg 2012; 256(2): 235-44.

[77] Hutton B, Fergusson D, Tinmouth A, et al. Transfusion rates vary significantly amongst Canadian medical centres. Can J Anaesth 2005; 52(6): 581-90.

[78] Yang X, Alexander KP, Chen AY, et al. The implications of blood transfusions for patients with non-ST-segment elevation acute coronary syndromes: results from the CRUSADE National Quality Improvement Initiative. J Am Coll Cardiol 2005; 46(8): 1490-5.

[79] Frank SM, Savage WJ, Rothschild JA, et al. Variability in blood and blood component utilization as assessed by an anesthesia information management system. Anesthesiology 2012; 117(1): 99 106.

[80] Seeber P, Shander A. Basics of blood management. Massachusetts: Blackwell Publishing 2008.

[81] Frenzel T, Van Aken H, Westphal M. Our own blood is still the best thing to have in our veins. Curr Opin Anaesthesiol 2008; 21(5): 657-63.

[82] Rosencrantz D, Shander A, Ozawa S, Spence R, eds. Transfusion medicine and alternatives to blood transfusion. Paris: R\&J Editions Medicales 2000

[83] Van der Linden P, Dierick A. Blood conservation strategies in cardiac surgery. Vox Sang 2007; 92(2): 103-12.

[84] Spahn DR, Casutt M. Eliminating blood transfusions: new aspects and perspectives. Anesthesiology 2000; 93(1): 242-55.

[85] Spiess BD, Spence R, Shander A, eds. Perioperative transfusion medicine. Philadelphia: Lippincott Williams \& Wilkins 2006.

[86] Kotter JP, Schlesinger LA. Choosing strategies for change. Harv Bus Rev 1979; 57(2): 106-14.

[87] Mukhtar S, Leahy M, Koay K, et al. Effectiveness of a patient blood management data system in monitoring blood use in Western Australia. Anaesth Intens Care 2013; 41(2): 207-15.

[88] Leahy MF, Roberts H, Mukhtar SA, et al. A pragmatic approach to embedding patient blood management in a tertiary hospital. Transfusion 2014; 54(4): 1133-45

[89] Jackson TJ, Michel JL, Roberts RF, et al. A classification of hospital-acquired diagnoses for use with routine hospital data. Med J Aust 2009; 191(10): 544-8. 
[90] SMHS. Patient Blood Management: Reducing anaemia, transfusions and length of stay for knee patients The Health Round Table 2012. Available from: https://http://www.healthroundtable.org/GetNews/tabid/668/itemid/172/amid/1858/patientblood-management-program-reducing-anaemia-transfusionslength-of-stay-f.aspx
[91] Isbister JP. Clinicians as gatekeepers: what is the best route to optimal blood use? Dev Biol (Basel) 2007; 127: 9-14.

[92] Jackson WL, Jr., Shorr AF. Blood transfusion and nosocomial infection: another brick in the wall. Crit Care Med 2006; 34(9): 2488-9.

Received: December 02, 2014

Revised: April 08, 2015

Accepted: April 08, 2015

(C) Farmer et al.; Licensee Bentham Open.

This is an open access article licensed under the terms of the Creative Commons Attribution Non-Commercial License (http://creativecommons.org/licenses/by-nc/3.0/) which permits unrestricted, non-commercial use, distribution and reproduction in any medium, provided the work is properly cited. 